\title{
APLIKASI PROGRAMMABLE LOGIC CONTROLLER (PLC) OMRON CP1E NA20 DRA DALAM PROSES PENGATURAN SISTEM KERJA MESIN PEMBUAT PELET IKAN
}

\author{
Tiar Kusuma Dewi, Priyo Sasmoko \\ Program Studi Diploma III Teknik Elektro \\ Fakultas Teknik Universitas Diponegoro
}

\begin{abstract}
Tiar Kusuma Dewi, Priyo Sasmoko, in paper application of programmable logic controller (PLC) omron CP1E NA20 DRA in control system of fish pellets builders engine explain that better known as PLC or Programmable Logic Controller is an electronic apparatus that works digitally, has a programmable memory, save the commands to perform specific functions such as logic, timing, counting and arithmatik to control different types of machines or processes through modules input / output analog or digital. PLC will run the display module according to the mnemonic code is entered into the PLC via the Programming Console or the $C X$ - Programmer programs. However, here are discussed PLC using the CX - Programmer. OMRON PLC used is CPIE NA2O DRA. PLC works by observing input (via sensors related), then the process and take action as needed, ie turn on or turn off the output (logic 0 or 1). Users create a program that will then be executed by the PLC in question, so that the tool Fish Pellet Machine Manufacturers Automatic will work as desired.
\end{abstract}

Keyword: OMRON PLC CPIE NA3O DRA, the CX - Programer

\section{PENDAHULUAN \\ Latar Belakang}

Ikan air tawar merupakan salah satu komoditas andalan hasil peternakan setelah komoditas unggas di Indonesia, hampir sebagian besar penduduk yang bertempat tinggal di daerah pedesaan memanfaatkan kondisi alam untuk berternak ikan. Namun hal ini masih kurang adanya dukungan dari sisi kebutuhan akan pelet atau pakan ikan yang masih membebani para petani ikan karena harga yang kurang terjangkau oleh sehingga mereka beralih ke dedaunan atau pakan alternative yang lebih murah. Hal ini berdampak pada kualitas ikan hasil ternaknya yang rendah.

Era sekarang ini kebutuhan konsumsi ikan semakin meningkat seiring dengan makin bertambahnya jumlah penduduk di Indonesia. Tetapi dengan meningkatnya permintaan konsumsi ikan ini, tidak memberikan pengaruh yang signifikan pada sector ekonomi para petani ikan. Hal ini disebabkan oleh melambungnya harga pelet ikan di pasaran. Oleh karena itu masalah ini harus mendapat perhatian yang serius dari berbagai pihak, termasuk di dalamnya mahasiswa.

Pokok dari masalah ini adalah bagaimana membuat suatu terobosan untuk menunjang kualitas hasil peternakan ikan yang sejalan dengan meningkatnya kesejahteraan para petani ikan. Salah satu terobosan dari segi teknologi adalah membuat suatu alat atau mesin yang mampu memproduksi pelet ikan dengan kualitas yang terjamin namun dengan biaya yang relative lebih murah sehingga tidak membebani para petani ikan dari segi biaya produksi.
Pokok Pembahasan

Dalam penelitian ini penyusun membahas masalah - masalah sebagai berikut :

- Pengenalan aplikasi pemrograman PLC OMRON CP1E NA20 DRA pada sistem pembuat pelet ikan otomatis dengan mengunakan $\mathrm{CX}$ - programmer.

- $\mathrm{CX}$ - programmer sebagai media pembuatan program aplikasi PLC pada system control mesin pembuat pelet ikan.

\section{LANDASAN TEORI \\ Catu Daya}

Catu daya merupakan komponen yang penting karena digunakan untuk mencatu daya suatu rangkaian agar dapat berfungsi atau bekerja. Catu daya dapat diperoleh dari baterai atau tegangan jala-jala PLN yang telah disearahkan. Komponen utama dari rangkaian ini adalah transformator, penyearah (dioda), penapis (kapasitor) dan IC regulasi.Prinsip dasar untuk memperoleh tegangan searah (DC) dari PLN dapat digambarkan dengan diagram blok pada gambar 1 .

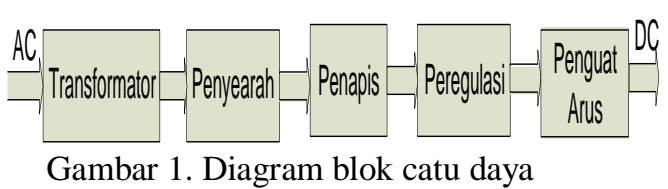

\section{PLC (Programmable Logic Controller)}

Pada prinsipnya sebuah PLC melalui modul sebuah input bekerja menerima data-data berupa sinyal dari peralatan input luar (external input device)dari sistem yang dikontrol. Peralatan input luar tersebut antara lain berupa saklar, tombol, 
sensor, dan lain-lain. Data-data masukan yang masih berupa sinyal analog akan diubah oleh modul input $\mathrm{A} / \mathrm{D}$ (analog to digital input module) menjadi sinyal digital. Selanjutnya oleh unit prosesor sentral atau CPU yang ada di dalam PLC sinyal digital dan disimpan di dalam ingatan (memory).

\section{Bagian-bagian dari Sebuah PLC}

Semua instruksi / perintah yang ada di bawah ini merupakan instruksi paling dasar pada PLC. Menurut aturan pemprograman, setiap akhir program PLC harus ada instruksi dasar END yang oleh PLC dianggap sebagai batas akhir dari program. Semua instruksi pemprograman PLC berupa ladder diagram dan bahasa pemprograman berupa kode mnemonic.

\section{- Load ( LD )}

Instruksi ini dibutuhkan jika urutan kerja (sequence) pada suatu sistem kontrol hanya membutuhkan satu kondisi logika saja dan sudah untuk mengeluarkan satu output. Logikanya seperti kontak NO Relay. Ladder Diagram simbol :

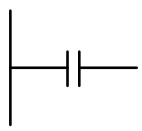

\section{- Load Not ( LD NOT )}

Instruksi ini dibutuhkan jika urutan kerja (sequence) pada suatu sistem kontrol hanya membutuhkan satu kondisi logika saja dan dituntut untuk mengeluarkan satu output. Logikanya seperti kontak NC Relay. Ladder Diagram simbol :

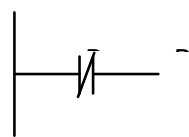

\section{- And ( AND )}

Instruksi ini dibutuhkan jika urutan kerja (sequence) pada suatu sistem kontrol membutuhkan lebih dari satu kondisi logika yang harus dipenuhi semuanya untuk mengeluarkan satu output. Logikanya seperti kontak NO Relay. Ladder Diagram simbol :

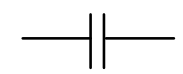

\section{- And Not ( AND NOT )}

Instruksi ini dibutuhkan jika urutan kerja (sequence) pada suatu sistem kontrol membutuhkan lebihnya satu kondisi logika yang harus terpenuhi semuanya untuk mengeluarkan satu output. Logikanya seperti kontak NC Relay. Ladder Diagram simbol :

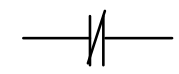

\section{- Or ( OR )}

Instruksi ini dibutuhkan jika urutan kerja (sequence) pada suatu sistem kontrol hanya membutuhkan salah satu saja beberapa kondisi logika untuk mengeluarkan satu output.

Logikanya seperti kontak NO Relay

Ladder Diagram simbol :

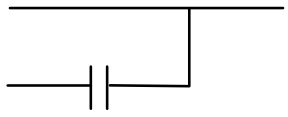

\section{- OR Not ( OR NOT )}

Instruksi ini dibutuhkan jika urutan kerja (sequence) pada suatu sistem kontrol hanya membutuhkan salah satu saja beberapa kondisi logika untuk mengeluarkan satu output. Logikanya seperti kontak NC Relay. Ladder Diagram simbol :

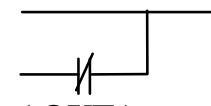

\section{- $\quad$ Out ( OUT )}

Instruksi ini berfungsi untuk mengeluarkan output jika semua kondisi ladder diagram sudah terpenuhi. Logikanya seperti kontak NO Relay. Laddder Diagram simbol :

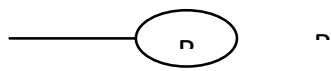

- $\quad$ End ( END (01) )

Instruksi ini berfungsi sebagai perintah akhir pada berbagai program. Setelah instruksi $\operatorname{END}(01)$, tidak ada instruksi lain yang dituliskan pada program. Apabila pada akhir program tidak dituliskan instruksi $\operatorname{END}(01)$, semua perintah yang terdapat pada program tidak dapat dijalankan, pada layar (display) akan muncul pesan kesalahan "NO END LIST". Simbol Ladder Diagram

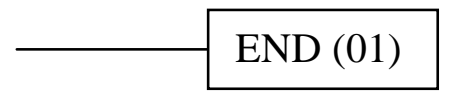

\section{Cx - Programmer}

CX-Programmer adalah software ladder untuk PLC merk Omron. Program ini beroperasi dibawah sistem operasi windows, oleh karena itu pengguna software ini diharapkan sudah familiar dengan program aplikasi, membuat file, menyimpan file, menutup file, membuka file, dan lain sebagainya.

PLC Omron dapat diprogram dengan menggunakan software CXProgrammer. Software ini dapat diperoleh di dealer-dealer Omron terdekat. Untuk dapat memogram PLC, PC tempat CX-Programmer diinstall harus dihubungkan ke CPU unit PLC dengan menggunakan kabel serial.

Setelah menghubungkan CPU unit dengan PC, setting PLC harus ditentukan. Cara penentuan setting PLC ada 2: Auto Online dan secara manual. 
Cara Auto Online adalah melakukan penyettingan PLC secara otomatis dengan membaca parameterparameter di PLC. Dengan menekan tombol Auto Online di toolbar atau memilih menu di PLC -> Auto Online -> Auto Online, parameter-parameter setting PLC seperti: urutan modul, alamat modul, jenis modul, dan isi program di CPU unit dapat ditransfer ke CX-Programmer.

Cara ini memudahkan kita karena hanya cukup mengklik satu tombol. Namun jika PLC sudah pernah diprogram, Auto Online dapat menghasilkan error message jika susunan modulmodul PLC tidak sama ketika diprogram dahulu kala. Dalam kasus ini, sebaiknya kita melakukan setting secara manual. Setting secara manual dilakukan dengan membuat project baru, kemudian memilih jenis PLC yang digunakan (Device Type). Lalu memasukkan jenis-jenismodul yang digunakan dengan cara memilih PLC -> Edit -> IO Table and Unit Setup.

\section{Sensor}

Sensor adalah alat yang digunakan untuk mendeteksi sesuatu dan sering berfungsi untuk mengukur magnitude. Sensor adalah jenis transduser yang digunakan untuk mengubah variasi mekanis, megnetis, panas, sinar dan kimia menjadi tegangan dan arus listrik.

\section{PRINSIP KERJA SISTEM}

Untuk mempermudah dalam memahami cara kerja rangkaian aplikasi phototransistor, driver relay, motor dc, dan motor ac sebagai kontrol pada proses pencampuran, mixer dan pencetakan pelet menggunakan PLC, maka disini dibuat blok diagram yang merupakan garis besar rangkaian tersebut. Diagram blok rangkaian tersebut ditunjukkan pada gambar 2 .

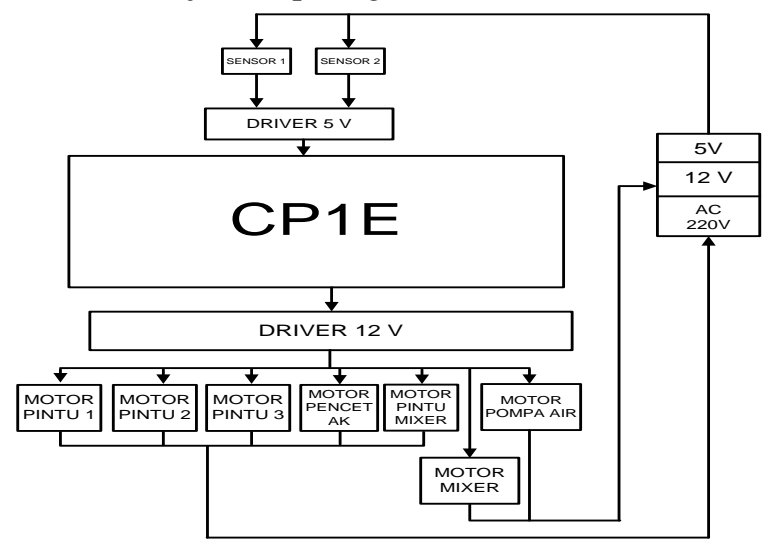

Gambar 2. Diagram blok sistem

\section{Flowchart}

Dari diagram blok tadi dapat dibuat flowchart dari mesin pembuat pelet ikan untuk lebih memahami langkah - langkah dari pembuatan pelet ikan tersebut. Flowchart daris sistem ini ditunjukkan pada gambar 3 .

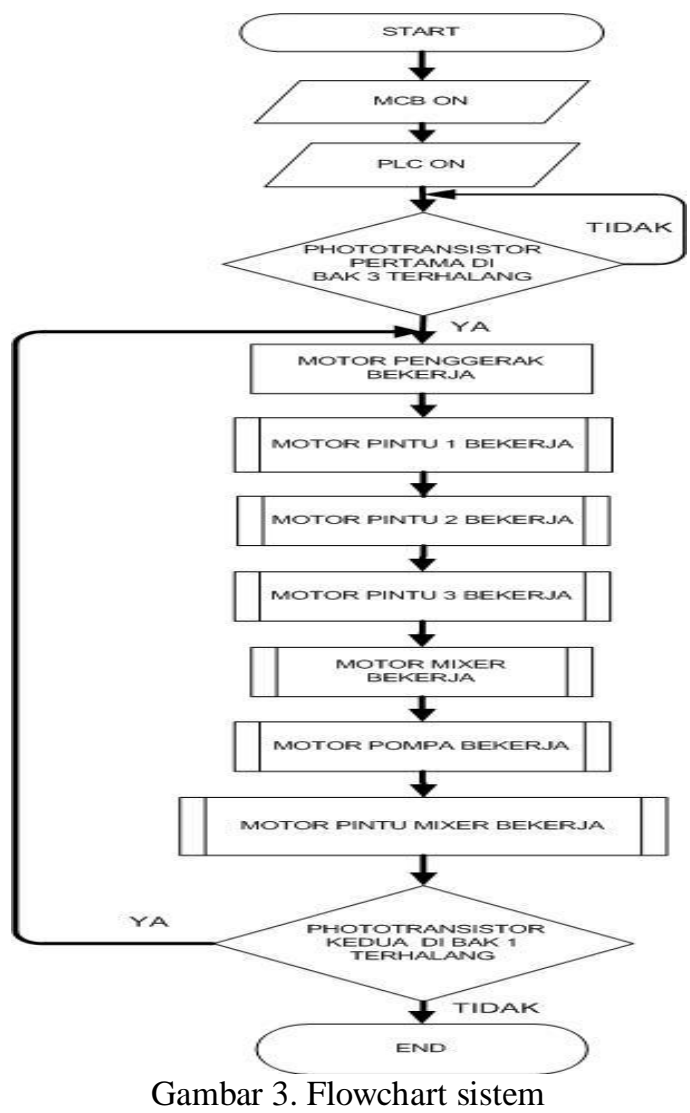

Cara Kerja Aplikasi PLC OMRON CP1E NA20 DRA Pada Mesin Pembuat Pelet ikan

Gambar 4 adalah diagram ladder dan tabel kode mnemonic dari program PLC CP1E-NA20 DRA pada mesin pembuat pelet ikan.

Proses pertama pada sistem ini adalah memasukkan bahan dasar kedalam bak penampung bahan secara berurutan sesuai dengan nomor yang ada. Ketika bahan dasar ke tiga dimasukkan maka phototransistor pertama dengan alamat 00000 akan terhalang dan proses terhalang tersebut sebagai inputan high dari alamat 00000 maka alamat tersebut akan menghidupkan output 10000 sebagai output bayangan. Dan ketika ouput 10000 ON maka ia akan memberi inputan high pada input dibaris berikutnya sehingga timer akan ON. Timer disini digunakan untuk mendelay pintu 1 supaya semua bahan masuk dedalam corong bahan dasar sesuai yang diinginkan. Selanjutnya ketika timer selesai maka dia akan bertindak sebagai input high pada baris selanjutnya sehingga output dengan alamat 10001 atau pintu satu akan ON. Output 10001 itu akan menjadi input dari timer selanjutnya. Timer 001 adalah sebagai delay atau waktu tunda dari hidupnya output dengan alamat 10002 atau pintu 2. Jadi apabila timer 001 selesai maka dia akan menjadi inputan high bagi output 10002. Sedangkan bagi output 10001 dengan hidupnya output 10002 berarti akan memberikan inputan low pada inputnya maka input 10002 akan memutus program sehingga output 10001 akan mati. Begitu seterusnya sampai dengan ouput 
dengan alamat 10004 yaitu motor mixer. Ouput 10001, 10002, 10003 dan 10004 akan OFF apabila salah satu dari output tersebut $\mathrm{ON}$ sehingga akan berjalan secarara bergantian. Tetapi untuk output 10005 akan hidup apabila output 10004 hidup tetapi output 10005 akan menghidupkan timer yang akan menunda waktu mati dari output tersebut. Sehingga ketika timer 005 selesai maka dengan otomatis output 10005 akan mati. Berbeda juga dengan jalanya output 10004, dia akan hidup ketika timer 006 belum selesai. Ouput 10004 akan memberikan input high pada timer 004 dan timer 004 akan menjadi inputan high ketika selesai kepada output 10006 yaitu pintu mixer tanpa mematikan motor mixer. Dan output 10006 akan menjadi inputan high bagi timer 006 yang fungsinya ketika selesai akan menghentikan jalanya kedua ouput yauitu output 10004 dan 10006. Fungsi lain dari timer 006 adalah untuk mengulang jalanya program dari awal yaitu akanmemberikan input high pada output 10000 yang sebagai ouput bayangan. Sedangkan untuk output 10007 ia akan hidup ketika ouput 10001 hidup dan memberikan inputan high sehingga ouput 10007 akan ON.

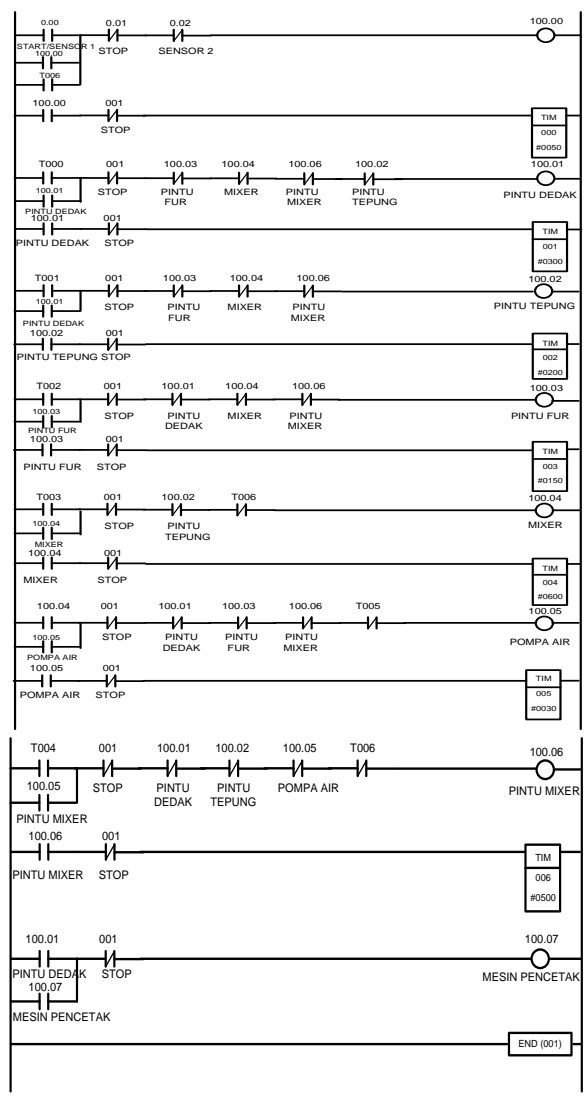

Gambar 4. Diagram ladder PLC

Apabila saat timer 006 selesai tetapi input 00002 high maka proses pembuatan pelet ikan akan selesai tetapi apabila inputan low maka proses akan berulang kembali sampai input tersebut high. Apabila terjadi kesalahan atau trouble pada mesin, dapat menghentikan system sementara dengan menekan tombol push button STOP pada alamat 00001 dan dapat mengoperasikannya kembali dengan menghalangi phototransistor pertama pada alamat 00000 menggunakan tangan atau benda lain tanpa memasukkan bahan baku lagi. Untuk urutan diagram mesin dapat dilihat pada gambar 6 .

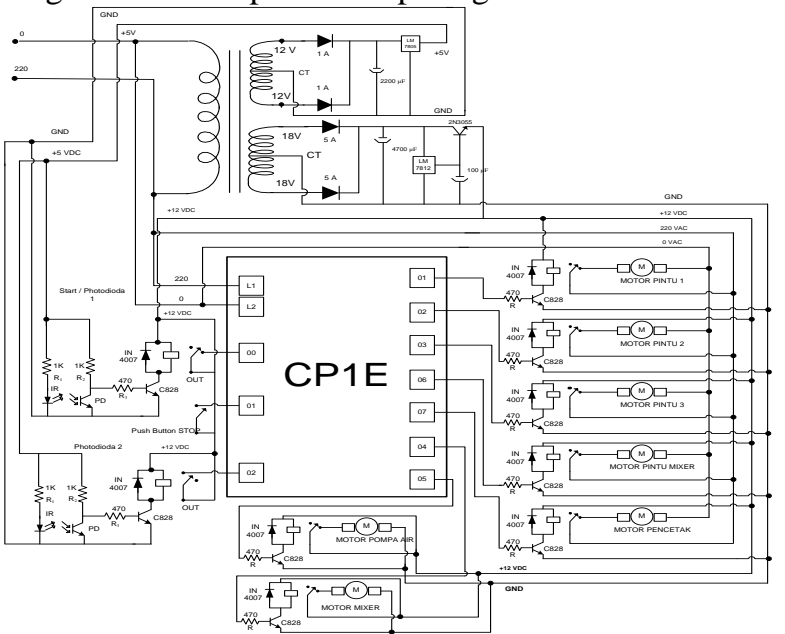

Gambar 5. Gambar rangkaian keseluruhan

\section{Input dan Output PLC Perblok}

Prinsip Kerja PLC merupakan peralatan kontrol berupa sinyal peralatan input luar (external input device), dari photodioda, start dan push button stop yang diterima oleh sebuah PLC. PLC akan memberikan perintah untuk mengerakkan peralatan output luar (external output device) dari sistem yang dikontrol berupa motor AC dan DC, yang nantinya untuk mengoperasikan sistem kerja mesin pembuat pelet ikan otomatis.

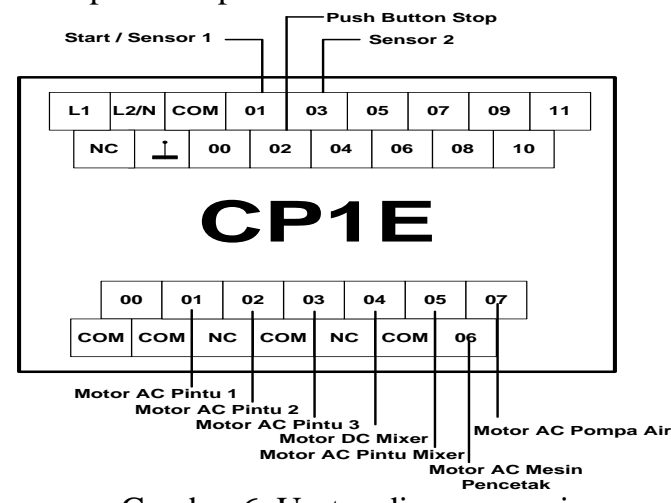

Gambar 6. Urutan diagram mesin

Bentuk fisik mesin pembuat pellet ikan dengan menggunakan PLC ditunjukkan pada gambar 7 . 


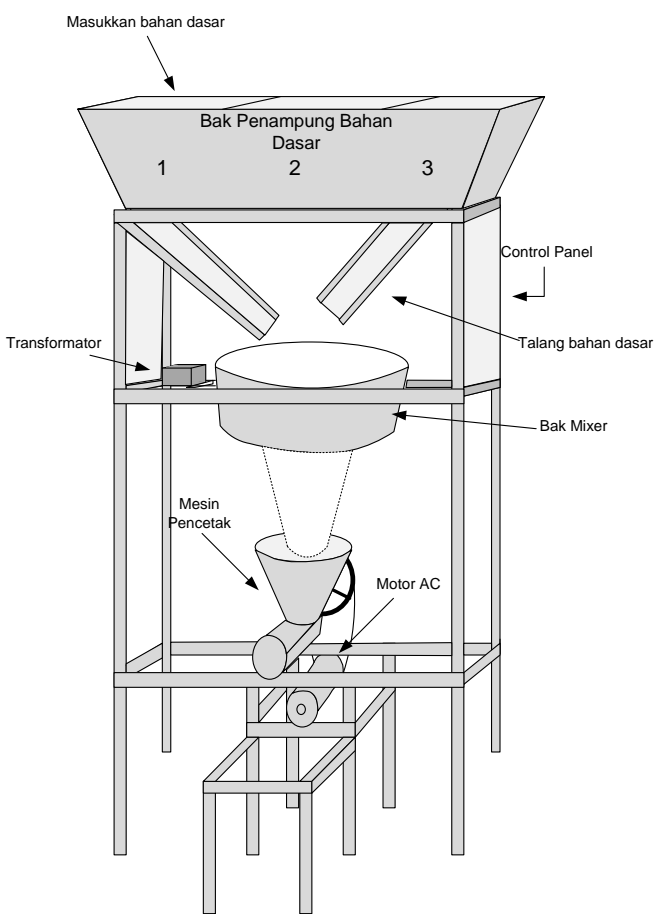

Gambar 7. Bentuk fisik mesin pembuat pelet ikan

\section{PENGUKURAN DAN ANALISA}

Pengukuran tidak hanya membahas pengukuran alat saja tapi juga tentang ruang lingkup yang lebih luas dari pengukuran meliputi tujuan dan langkah pengukuran. Sedangkan pengukuran sendiri membahas tentang alat dan bahan yang digunakan, langkah pengukuran pada masing-masing blok rangkaian yang meliputi pengukuran input output PLC maupun pengukuran rangkaian aplikasi catu daya, phototransistor, motor - motor dc dan motor - motor ac.

\section{Data Hasil Pengukuran}

Pengukuran dilakukan pada komponenkomponen yang digunakan dalam sistem mesin pembuat pellet ikan ini. Hasil pengukuran ditunjukkan pada tabel 1, 2, 3, 4, 5, 6 dan 7 .

Tabel 1. Hasil Pengukuran Catu Daya $12 \mathrm{~V}_{\mathrm{DC}}$

\begin{tabular}{ccc}
\hline V input & Titik Pengukuran & V output \\
AC & Setelah Dioda 5A & $25,3 \mathrm{~V}_{\mathrm{DC}}$ \\
\hline $18 \mathrm{~V}$ & Setelah Capasitor & $25,5 \mathrm{~V}_{\mathrm{DC}}$ \\
$18 \mathrm{~V}$ & $4700 \mu \mathrm{F}$ & $+12 \mathrm{~V}_{\mathrm{DC}}$ \\
$18 \mathrm{~V}$ & Setelah IC LM7812 & $12 \quad$ DC \\
$18 \mathrm{~V}$ & Setelah Transistor & \\
\hline
\end{tabular}

Tabel 2. Hasil Pengukuran Catu Daya $5 \mathrm{~V}_{\mathrm{DC}}$

\begin{tabular}{ccc}
\hline $\begin{array}{c}\text { V input } \\
\text { AC }\end{array}$ & Titik Pengukuran & V output \\
\hline $12 \mathrm{~V}$ & Setelah Dioda 1A & $16,9 \mathrm{~V}_{\mathrm{DC}}$ \\
$12 \mathrm{~V}$ & Setelah Capasitor & $17,1 \mathrm{~V}_{\mathrm{DC}}$ \\
$12 \mathrm{~V}$ & Setelah IC LM7805 & $+5 \mathrm{~V}_{\mathrm{DC}}$ \\
\hline
\end{tabular}

Tabel 3. Hasil Pengukuran Phototransistor

\begin{tabular}{ccccc}
\hline $\begin{array}{c}\text { Aplika } \\
\text { si }\end{array}$ & Kondisi & $\begin{array}{c}\text { Tegangan } \\
\text { (Volt) }\end{array}$ & $\begin{array}{c}\text { Output } \\
\text { (Volt) }\end{array}$ & $\begin{array}{c}\text { Arus } \\
\text { (Am } \\
\text { pere) }\end{array}$ \\
\hline $\begin{array}{c}\text { Phototr } \\
\text { ansisto } \\
\text { r }\end{array}$ & $\begin{array}{c}\text { Terang } \\
\text { (Sistem } \\
\text { off) } \\
\text { Gelap }\end{array}$ & $1,8 \mathrm{~V}_{\mathrm{DC}}$ & 1,7 & 20 \\
& $0 \mathrm{~V}_{\mathrm{DC}}$ & $0 \mathrm{~V}_{\mathrm{DC}}$ & 0 \\
\hline
\end{tabular}

Tabel 4. Hasil Pengukuran motor penarik pintu

\begin{tabular}{llll}
\hline Aplikasi Kondisi & $\begin{array}{l}\text { Tegangan } \\
\text { (Volt) }\end{array}$ & $\begin{array}{l}\text { Arus } \\
\text { (Ampere) }\end{array}$ \\
\hline Motor & Menarik & $220 \mathrm{~V}$ & $0,018 \mathrm{~A}$ \\
Pintu & Tidak menarik & $0 \mathrm{~V}$ & 0 \\
\hline
\end{tabular}

Tabel 5. Hasil Pengukuran motor mixer

\begin{tabular}{llcc}
\hline Aplikasi & Kondisi & $\begin{array}{l}\text { Tegangan } \\
\text { (Volt) }\end{array}$ & $\begin{array}{l}\text { Arus } \\
\text { (Ampere) }\end{array}$ \\
\hline $\begin{array}{l}\text { Motor } \\
\text { mixer }\end{array}$ & $\begin{array}{l}\text { Berputar } \\
\text { Tidak } \\
\text { berputar }\end{array}$ & $12 \mathrm{~V}_{\mathrm{DC}}$ & $3,1 \mathrm{~A}$ \\
\hline
\end{tabular}

Tabel 6. Hasil Pengukuran motor pompa

\begin{tabular}{lllcl}
\hline Aplikasi & Kondisi & $\begin{array}{l}\text { Tegangan } \\
\text { (Volt) }\end{array}$ & $\begin{array}{l}\text { Arus } \\
\text { (Ampere) }\end{array}$ \\
\hline $\begin{array}{l}\text { Motor } \\
\text { pompa }\end{array}$ & Menyemprot & $12 \mathrm{~V}_{\mathrm{DC}}$ & $0,01 \mathrm{~A}$ & $\begin{array}{l}\text { Tidak } \\
\text { menyemprot }\end{array}$ \\
\hline
\end{tabular}

Tabel 7. Hasil Pengukuran motor pencetak

\begin{tabular}{llll}
\hline Aplikasi & Kondisi & $\begin{array}{l}\text { Tegangan } \\
\text { (Volt) }\end{array}$ & $\begin{array}{l}\text { Arus } \\
\text { (Ampere) }\end{array}$ \\
\hline & $\begin{array}{l}\text { Berputar } \\
\text { tanpa beban }\end{array}$ & $220 \mathrm{~V}$ & $3 \mathrm{~A}$ \\
$\begin{array}{l}\text { Motor } \\
\text { ac }\end{array}$ & $\begin{array}{l}\text { Berputar } \\
\text { berbeban } \\
\text { Tidak } \\
\text { berputar }\end{array}$ & $218,5 \mathrm{~V}$ & $3,3 \mathrm{~A}$ \\
& $0 \mathrm{~V}$ & $0 \mathrm{~A}$ \\
\hline
\end{tabular}

\section{Pengujian Alat}

Pengujian dilakukan untuk mengetahui apakah alat yang dibuat bekerja dengan baik sesuai dengan program yang telah dirancang. Pengecekan dapat dilakukan dengan melihat lampu indikator pada PLC setelah seluruh rangkaian dipasang. Pengecekan dilakukan sebelum dan sesudah PLC diprogram. Berikut ini adalah data hasil pengujian 
alat yang dibuat melalui input dan output PLC. Hasilnya ditunjukkan pada tabel 8 dan 9 .

\section{PENUTUP}

\section{Kesimpulan}

Dari percobaan alat dan pengukuran sistem tersebut dapat ditarik kesimpulan sebagai berikut:

- Menurut hasil pengujian output, selisih waktu yang diatur dalam PLC dengan waktu yang terukur adalah $0,002 \%$.

- Air yang dialirkan belum mampu membuat campuran tepung ikan, konsentrat dan dedak tercampur dengan baik.

\section{Saran}

Saran-saran yang disampaikan dalam penelitian ini adalah sebagai berikut :

- Sebaiknya kendali proses harus dipahami oleh operator agar tidak terjadi kesalahan dalam menjalankan sistem.

- Komponen-komponen listrik yang akan digunakan dipastikan berfungsi dengan baik.

- Perawatan pada mesin ini sebaiknya dilakukan secara berkala untuk menghindari adanya penurunan sistem kerja alat ini.

- Untuk lebih memudahkan para peternak ikan dalam membuat pelet ikan, sebaiknya alat ini diberi konveyor dan pemotong yang bisa disesuaikan ukuran pemotonganya sesuai dengan tujuan alat ini yang bersifat universal.

- Untuk pencampuran tepung ikan konsentrat dan dedak air yang dipompakan perlu deprogram secara kontinyu.

\section{DAFTAR PUSTAKA}

1. Achmad Afandi, Fikri. 2007. Aplikasi Phototransistor sebagai Switch PLC (Programmable Logic Controller) dalam Pengaturan Solenoid dan Thermocouple sebagai Pengendali Suhu pada Mesin Penggiling Biji Kopi Otomatis. Semarang : Universitas Diponegoro.

2. Bishop, Owen. 2004. Dasar-Dasar Elektronika. Jakarta: Erlangga.

3. Eko Putra, Agfianto. 2004. PLC : Konsep, Pemprograman dan Aplikasi (Omron CPM1A/CPM2A dan ZEN Programmable Relay). Yogyakarta: GAVAMEDIA.

4. Hasan, Esan. 2000. Rangkaian Dasar Elektronika. Bandung Ganesa: Exact.

5. Malvino, Albert Paul. 1994. Prinsip-Prinsip Elektronika. Jakarta: Erlangga.

6. Mukti Hermawan, Tri. 2009. Aplikasi PLC SYSMAC OMRON CPM1A 30I/O dengan Sensor Limit Switch RX KW12 pada Pintu Gerbang Otomatis sebagai Bagian Sistem Otomatisasi Rumah. Semarang : Universitas Diponegoro.
7. Pancamanunggal. Buku Panduan Training PLC OMRON Tingkat Dasar. Jakarta : Pancamanunggal.

8. Setiawan, Hendrix. 2007. Aplikasi dan Pemprograman Programmable Logic Controller (PLC) dalam Proses Pengaturan Sistem Kerja Mesin Penggiling Biji Kopi Otomatis . Semarang : Universitas Diponegoro.

9. Suwanto. 2005. Aplikasi PLC sebagai Penentuan Kecepatan Putar Motor DC dengan Indikator Lampu 220V AC Menggunakan Programming Console. Semarang: Universitas Diponegoro.

10. Widyaningrum, Widi. 2012. Aplikasi Programmable Logic Controller (PLC) Omron CPM1A-10CDR Pada Sistem Pemanas Mesin Penggiling Biji Kopi Otomatis. Semarang : Universitas Diponegoro.

11. Zuhal dan Zhanggischan. 2004. Prinsip Dasar Elektroteknik. Jakarta: PT Gramedia Pustaka Utama. 
Tabel 8. Hasil pengujian input PLC

\begin{tabular}{|l|l|l|l|l|}
\hline $\begin{array}{l}\text { Alamat } \\
\text { Input } \\
\text { PLC }\end{array}$ & Aplikasi & Kondisi & Ket & Sebab \\
\cline { 3 - 5 } 00000 & $\begin{array}{l}\text { Start / Photo } \\
\text { transistor 1 }\end{array}$ & ON & Sebagai switch PLC otomatis & cahaya LED terhalang bahan dasar \\
\cline { 2 - 5 } & OFF & PLC tetap bekerja & Phototransistor mendapat sumber cahaya \\
\hline 00001 & Push Button Stop & ON & $\begin{array}{l}\text { Un } \\
\text { tuk meg } \\
\text { hentikan mesin }\end{array}$ & Kontak akan terputus \\
\hline 00002 & $\begin{array}{l}\text { Photo } \\
\text { transistor 2 }\end{array}$ & ON & $\begin{array}{l}\text { Seb } \\
\text { agai switch PLC oto } \\
\text { matis }\end{array}$ & cahaya LED terhalang bahan dasar \\
\cline { 2 - 5 } & OFF & PLC tidak bekerja & Phototransistor mendapat sumber cahaya \\
\hline
\end{tabular}

Tabel 9. Hasil pengujian output PLC

\begin{tabular}{|c|c|c|c|c|c|c|c|c|c|c|c|}
\hline \multirow{2}{*}{$\begin{array}{l}\text { Alamat } \\
\text { Output } \\
\text { PLC }\end{array}$} & \multirow[t]{2}{*}{ Aplikasi } & \multirow{2}{*}{$\begin{array}{l}\text { Kond } \\
\text { isi }\end{array}$} & \multirow[t]{2}{*}{ Ket } & \multirow[t]{2}{*}{ Sebab } & \multicolumn{5}{|c|}{$\begin{array}{l}\text { Waktu } \\
\text { Percobaan }\end{array}$} & \multirow[t]{2}{*}{ Setting } & \multirow[t]{2}{*}{ Selisih } \\
\hline & & & & & 1 & 2 & 3 & 4 & $\mathbf{R}^{2}$ & & \\
\hline 100.00 & $\begin{array}{l}\text { Output } \\
\text { Bayangan }\end{array}$ & $\mathrm{ON}$ & $\begin{array}{l}\text { Lampu Output pada PLC } \\
\text { menyala }\end{array}$ & $\begin{array}{l}\text { Mendapat inputan “1” dari } \\
\text { sensor 1 }\end{array}$ & - & - & - & - & - & - & - \\
\hline T000 & Timer 1 & ON & Output 10001 terdelay & $\begin{array}{l}\text { Mendapat inputan "1" dari } \\
\text { Output } 10000\end{array}$ & $4,7 \mathrm{~s}$ & $4,6 \mathrm{~s}$ & $4,9 \mathrm{~s}$ & $5,1 \mathrm{~s}$ & $4,8 \mathrm{~s}$ & $5 \mathrm{~s}$ & $0,2=0.002 \%$ \\
\hline \multirow[t]{2}{*}{10001} & \multirow{2}{*}{$\begin{array}{l}\text { Motor } \\
\text { penarik } \\
\text { pintu bak } 1\end{array}$} & ON & $\begin{array}{l}\text { Motor penenarik pintu } \\
\text { bak pertama aktif }\end{array}$ & $\begin{array}{l}\text { PLC mendapat input "1" dari } \\
\text { Phototransistor } 1\end{array}$ & $29,8 \mathrm{~s}$ & $29,5 \mathrm{~s}$ & $30,2 \mathrm{~s}$ & $29,9 \mathrm{~s}$ & $29.8 \mathrm{~s}$ & $30 \mathrm{~s}$ & $0,2=0,002 \%$ \\
\hline & & OFF & $\begin{array}{l}\text { Motor penenarik pintu } \\
\text { bak pertama mati }\end{array}$ & $\begin{array}{l}\text { PLC mendapat input " } 0 \text { " dari } \\
\text { timer }\end{array}$ & - & - & - & - & & - & - \\
\hline T001 & Timer 2 & ON & Output 10002 terdelay & $\begin{array}{l}\text { Mendapat inputan "1" dari } \\
\text { Output } 10001\end{array}$ & $29,8 \mathrm{~s}$ & $29,5 \mathrm{~s}$ & $30,2 \mathrm{~s}$ & $29,9 \mathrm{~s}$ & $29.8 \mathrm{~s}$ & $30 \mathrm{~s}$ & $0,2=0,002 \%$ \\
\hline \multirow[t]{2}{*}{10002} & \multirow{2}{*}{$\begin{array}{l}\text { Motor } \\
\text { penarik } \\
\text { pintu bak } 2\end{array}$} & $\mathrm{ON}$ & $\begin{array}{l}\text { Motor penenarik pintu } \\
\text { bak pertama aktif }\end{array}$ & $\begin{array}{l}\text { PLC mendapat input " } 1 \text { " dari } \\
\text { timer }\end{array}$ & $19,5 \mathrm{~s}$ & $20,3 \mathrm{~s}$ & $19,8 \mathrm{~s}$ & $19,7 \mathrm{~s}$ & $19,8 \mathrm{~s}$ & $20 \mathrm{~s}$ & $0,2=0,002 \%$ \\
\hline & & OFF & $\begin{array}{l}\text { Motor penenarik pintu } \\
\text { bak pertama mati }\end{array}$ & $\begin{array}{l}\text { PLC mendapat input " } 0 \text { " dari } \\
\text { timer }\end{array}$ & - & - & - & - & - & - & - \\
\hline T002 & Timer 3 & $\mathrm{ON}$ & Output 10003 terdelay & Mendapat inputan "1" dari & $19,5 \mathrm{~s}$ & $20,3 \mathrm{~s}$ & $19,8 \mathrm{~s}$ & $19,7 \mathrm{~s}$ & $19,8 \mathrm{~s}$ & $20 \mathrm{~s}$ & $0,2=0,002 \%$ \\
\hline
\end{tabular}




\begin{tabular}{|c|c|c|c|c|c|c|c|c|c|c|c|}
\hline & & & & Output 10002 & & & & & & & \\
\hline \multirow[t]{2}{*}{10003} & \multirow{2}{*}{$\begin{array}{l}\text { Motor } \\
\text { penarik } \\
\text { pintu bak } 3\end{array}$} & $\mathrm{ON}$ & $\begin{array}{l}\text { Motor penenarik pintu } \\
\text { bak pertama aktif }\end{array}$ & $\begin{array}{l}\text { PLC mendapat input " } 1 \text { " dari } \\
\text { timer }\end{array}$ & $15,2 \mathrm{~s}$ & $14,8 \mathrm{~s}$ & $15,1 \mathrm{~s}$ & $15,3 \mathrm{~s}$ & $15,1 \mathrm{~s}$ & $15 \mathrm{~s}$ & $0,1=0,001 \%$ \\
\hline & & OFF & $\begin{array}{l}\text { Motor penenarik pintu } \\
\text { bak pertama mati }\end{array}$ & $\begin{array}{l}\text { PLC mendapat input " } 0 \text { " dari } \\
\text { timer }\end{array}$ & - & - & - & - & - & - & - \\
\hline T003 & Timer 4 & $\mathrm{ON}$ & Output 10004 terdelay & $\begin{array}{l}\text { Mendapat inputan "1" dari } \\
\text { Output } 10003\end{array}$ & $15,2 \mathrm{~s}$ & $14,8 \mathrm{~s}$ & $15,1 \mathrm{~s}$ & $15,3 \mathrm{~s}$ & $15,1 \mathrm{~s}$ & $15 \mathrm{~s}$ & $0,1=0,001 \%$ \\
\hline \multirow[t]{2}{*}{10004} & \multirow[t]{2}{*}{ Motor mixer } & $\mathrm{ON}$ & Motor mixer aktif & $\begin{array}{l}\text { PLC mendapat input " } 1 \text { " dari } \\
\text { timer }\end{array}$ & $59,4 \mathrm{~s}$ & $60,3 \mathrm{~s}$ & $60,1 \mathrm{~s}$ & $59,7 \mathrm{~s}$ & $59.8 \mathrm{~s}$ & $60 \mathrm{~s}$ & $0,2=0,002 \%$ \\
\hline & & OFF & Motor mixer mati & $\begin{array}{l}\text { PLC mendapat input " } 0 \text { " dari } \\
\text { timer }\end{array}$ & - & - & - & - & - & - & - \\
\hline T004 & Timer 5 & ON & Output 10006 terdelay & $\begin{array}{l}\text { Mendapat inputan " } 1 " \text { dari } \\
\text { Output } 10004\end{array}$ & $59,4 \mathrm{~s}$ & $60,3 \mathrm{~s}$ & $60,1 \mathrm{~s}$ & $59,7 \mathrm{~s}$ & $59.8 \mathrm{~s}$ & $60 \mathrm{~s}$ & $0,2=0,002 \%$ \\
\hline \multirow[t]{2}{*}{10005} & \multirow[t]{2}{*}{$\begin{array}{l}\text { Motor } \\
\text { pompa }\end{array}$} & $\mathrm{ON}$ & Motor pompa hidup & $\begin{array}{l}\text { PLC mendapat input " } 1 \text { " dari } \\
\text { timer }\end{array}$ & $3,2 \mathrm{~s}$ & $3,4 \mathrm{~s}$ & $3,1 \mathrm{~s}$ & $3,5 \mathrm{~s}$ & $3,3 \mathrm{~s}$ & $3 \mathrm{~s}$ & $0,3=0,003 \%$ \\
\hline & & OFF & Motor pompa mati & $\begin{array}{l}\text { PLC mendapat input " } 0 \text { " dari } \\
\text { timer }\end{array}$ & - & - & - & - & - & - & - \\
\hline T005 & Timer 6 & $\mathrm{ON}$ & $\begin{array}{l}\text { Output } 10005 \text { terdelay } \\
\text { untuk mati }\end{array}$ & $\begin{array}{l}\text { Mendapat inputan “1” dari } \\
\text { Output } 10005\end{array}$ & $3,2 \mathrm{~s}$ & $3,4 \mathrm{~s}$ & $3,1 \mathrm{~s}$ & $3,5 \mathrm{~s}$ & $3,3 \mathrm{~s}$ & $3 \mathrm{~s}$ & $0,3=0,003 \%$ \\
\hline \multirow[t]{2}{*}{10006} & \multirow{2}{*}{$\begin{array}{l}\text { Motor } \\
\text { penarik } \\
\text { pintu bak } \\
\text { mixer }\end{array}$} & $\mathrm{ON}$ & $\begin{array}{l}\text { Motor penenarik pintu } \\
\text { bak mixer aktif }\end{array}$ & $\begin{array}{l}\text { PLC mendapat input " } 1 \text { " dari } \\
\text { timer }\end{array}$ & $50,6 \mathrm{~s}$ & $50,2 \mathrm{~s}$ & $49,5 \mathrm{~s}$ & $50,3 \mathrm{~s}$ & $50,1 \mathrm{~s}$ & $50 \mathrm{~s}$ & $0,1=0,001 \%$ \\
\hline & & OFF & $\begin{array}{l}\text { Motor penenarik pintu } \\
\text { bak mixer mati }\end{array}$ & $\begin{array}{l}\text { PLC mendapat input " } 0 \text { " dari } \\
\text { timer }\end{array}$ & - & - & - & - & - & - & - \\
\hline T006 & Timer 7 & $\mathrm{ON}$ & $\begin{array}{l}\text { Output } 10004 \text { dan } 10006 \\
\text { terdelay untuk mati }\end{array}$ & $\begin{array}{l}\text { Mendapat inputan "1" dari } \\
\text { Output } 10006\end{array}$ & $50,6 \mathrm{~s}$ & $50,2 \mathrm{~s}$ & $49,5 \mathrm{~s}$ & $50,3 \mathrm{~s}$ & $50,1 \mathrm{~s}$ & $50 \mathrm{~s}$ & $0,1=0,001 \%$ \\
\hline \multirow{2}{*}{100007} & \multirow[t]{2}{*}{ Motor AC } & $\mathrm{ON}$ & Motor AC aktif & $\begin{array}{l}\text { PLC mendapat input " } 1 \text { " dari } \\
\text { Phototransistor } 1\end{array}$ & $\begin{array}{l}183,5 \\
\mathrm{~s}\end{array}$ & $\begin{array}{l}183,7 \\
\mathrm{~s}\end{array}$ & $\begin{array}{l}182,3 \\
\mathrm{~s}\end{array}$ & $\begin{array}{l}184,2 \\
\mathrm{~s}\end{array}$ & $183.4 \mathrm{~s}$ & $183 \mathrm{~s}$ & $0,4=0,004 \%$ \\
\hline & & OFF & Motor AC mati & $\begin{array}{l}\text { PLC mendapat input " } 1 \text { " dari } \\
\text { Phototransistor } 2\end{array}$ & - & - & - & - & - & - & - \\
\hline
\end{tabular}

